American Journal of Applied Sciences 6 (5): 888-896, 2009

ISSN 1546-9239

(C) 2009 Science Publications

\title{
Development of Vegetable Based Milk from Decorticated Sesame (Sesamum Indicum)
}

\author{
${ }^{1}$ Jihad M. Quasem, ${ }^{2}$ Ayman Suliman Mazahreh and ${ }^{3}$ Khaled Abu-Alruz \\ ${ }^{1}$ Department of Planning, Development and Quality Assurance Affaires, \\ Al-Balqa Applied University, Zarka University College, Zarka, Jordan \\ ${ }^{2}$ Department of Applied Science, Al-Balqa Applied University, \\ Princes Alia University College, P.O. Box 941941, Zarqa 11194 Jordan \\ ${ }^{3}$ Department of Food Science and Nutrition, Faculty of Allied Medical Sciences, \\ Applied Science University, Amman, Jordan
}

\begin{abstract}
Problem statement: Decorticated sesame seed can supply us with nutritious, functional and healthy meals with relatively low cost. These properties make sesame a valuable source of protein and other nutrients to be utilized in imitated dairy products, which could be used for infant and adults with lactose intolerance as well as for vegetarian or others who like to eat dairy products free from cholesterol. Additionally, the production of sesame-based dairy products can overcome the problems that limit consumption of soy-based dairy products such as antinutritional factors, flavor and flatulence. The major challenges in developing dairy analogs from plant sources are: unacceptable flavor, low solids yield and low dispersion stability. Approach: The following factors were investigated to increase/optimize the sesame milk yield, dispersion stability and sensory acceptance: pretreatment of sesame seed with simple physical treatments (soaking in water, boiling, pressure cooking, steaming and combination treatments) and heat treatment of sesame milk (pasteurization or sterilization). Results: Heat treatments during all steps of processing proved to be the most important factor in determining the yield and quality of sesame milk. The best treatment was pasteurized sesame milk $\left(75^{\circ} \mathrm{C}\right.$ for $5 \mathrm{~min}$ ) with $12 \%$ initial sesame seed concentration (previously dried at $170^{\circ} \mathrm{C}$ for $5 \mathrm{sec}$ ) and formulated with the addition of $2 \%$ sucrose. Conclusion: The developed procedure for sesame milk production resulted in high yield, excellent dispersion stability and good sensory acceptability.
\end{abstract}

Key words: Sesame milk, sensory evaluation, pretreatments, dispersion stability, yield

\section{INTRODUCTION}

Much attention has been given to soymilk and soy protein beverages as they are considered to be nutritious and healthy foods ${ }^{[7]}$. In addition to soymilk, potential production of other vegetable milks was investigated in other oilseeds and legumes: Bambara groundnut ${ }^{[4]}$, chick peas, pigeon peas, black graw, mung beans, coconut, cowpeas ${ }^{[16]}$, lupin, peanuts, sunflower ${ }^{[3,5]}$.

Recently, much attention has been directed toward exploring the utilization of oilseeds in general ${ }^{[10]}$ and sesame seed in special ${ }^{[11]}$ for new food uses on the basis of their functional properties. Decorticated sesame seed can supply us with nutritious ${ }^{[3,6]}$ functional $^{[14]}$ and healthy meals ${ }^{[8,12,13,18]}$ with relatively low cost.

The production of sesame-based dairy products can overcome the problems that limit consumption of soybased dairy products and other vegetable milk such as presence of anti-nutritional factors, Beany and astringent flavor low solids yield, Low dispersion stability flatulence factors ${ }^{[4,7,15]}$.

Decorticated sesame seed have the following composition: $45-63 \%$ (averaging about 50\%) oil, 19$31 \%$ (averaging about 25\%) proteins, about $14 \%$ carbohydrate and about 3\% ash. Sesame is rich in sulfur-containing amino acids and limited in lysine and contains significant amounts of oxalic (2.5\%) and phytic acids $(5 \%)^{[9]}$. Because oxalic acid is present in the hulls, decortication can remove most of $\mathrm{it}^{[19]}$. Unlike many oilseeds, sesame meal is devoid of antitryptic compounds. Sesame seed oil is rich in unsaturated fatty acids where the fatty acids composition is $14 \%$ saturated fatty acids, 39\% mono-unsaturated and 46\% poly-unsaturated ${ }^{[19]}$. Carbohydrates in sesame seed are composed from $3.2 \%$ glucose, $2.6 \%$ fructose and $0.2 \%$ sucrose and the remaining quantities seem to be dietary

Corresponding Author: Jihad M. Quasem, Department of Planning, Development and Quality Assurance Affaires,

Al-Balqa Applied University, Zarka University College, Zarka, Jordan 
fibers. Also, they have desirable physiological effects including antioxidant, blood pressure and serum lipid lowering in experimental animals and humans ${ }^{[18]}$.

The major protein fraction (globulin) in sesame contains about $95 \%$ of a $13 \mathrm{~S}$ globulin and seems to be a simple, salt soluble, very susceptible to heat denaturation and similar in subunit structure to soybean $11 \mathrm{~S}$ globulin with more hydrophobic properties. The last property limits the use of sesame proteins in certain food formulation, particularly in fluids and beverages, which indicates the need for modifying the functionality of sesame proteins before it can be used in processing of imitated dairy products. Functional properties reflect the intrinsic physical attributes of the protein as influenced by interactions with food components and the processing treatments ${ }^{[9]}$. Defatting, Roasting, puffing, pressure-cooking, microwave cooking, germination, fermentation ${ }^{[10]}$ and soaking were used to modify the functional properties of sesame seed and its meal. Despite of these studies, the predictive value of functional properties parameters (nitrogen solubility index, emulsion capacity and stability, foaming capacity and stability and water and fat binding capacity) for determining the behavior of oilseed meals in actual food systems is far from straightforward, therefore there is a need to evaluate these methods in actual food system.

The objective of this study was to study the most appropriate pre-treatments of sesame seed to increase its functional properties that produce a stable emulsion/dispersion with most acceptable flavor.

\section{MATERIALS AND METHODS}

Sesame seed: Two sources of decorticated sesame seed were used; the first (originated from Sudan) was obtained from Al-Nahda Pressing Mill Company in Marka/Jordan and characterized by a slightly perceived bitter aftertaste. The second (originated from Ethiopia) obtained from Al-Kasih Factories Group for Food Stuff in Zarqqa/Jordan and characterized as sweet sesame (bitter taste was absent). The two types were differed mainly in their drying temperatures after decortication process. Sesame seed from the first source was obtained from the source and directly dried overnight at temperature not exceeding $55^{\circ} \mathrm{C}$ using a drying oven, whereas the sesame from the second source was dried at $170^{\circ} \mathrm{C}$ for $5 \mathrm{sec}$ using a commercial fluidized bed drier located in Al-Kasih factory.

Instruments: The following instruments were used throughout the study: Blender (Hamilton), homogenizer (Silverson), drying oven (Memmert, Germany), Kjeldahl Apparatus (Velp Scientifica, Italy).
Basic steps of sesame milk preparation: The proposed procedure followed in sesame milk production is shown in Fig. 1. First, decorticated sesame seed and tap water were weighed to give the desired sesame seed percentage $(12 \% \mathrm{wt} / \mathrm{wt})$. Sesame seed was transferred to the blender vessel and a small portion of the weighed water was added to facilitate the progress of mixing/grinding process. The blender was operated at highest speed for $10 \mathrm{~min}$. After finishing the grinding process, the remaining quantity of water was added and mixed thoroughly. The resulted sesame dispersion was homogenized (in portions of $300 \mathrm{~g}$ ) for 5 min using lab homogenizer. The temperature reached due to homogenization was ca. $522^{\circ} \mathrm{C}$. The homogenized sesame milk base was squeezed through cheesecloth to separate coarse particles. The resulted milky solution was weighed, readjusted to its original weight (before filtration) by adding tap water, mixed thoroughly and heat-treated (by pasteurization or sterilization). For pasteurization, sesame milk was filled in a beaker and heated in boiling water bath with manual stirring, while for sterilization the sesame milk was filled in $100 \mathrm{~mL}$ glass tubes and sterilized at $121^{\circ} \mathrm{C}$ for $20 \mathrm{~min}$ using autoclave. The heat-treated milks was filled in $50 \mathrm{~mL}$ presterilized medical tubes $(50 \mathrm{~mL}$ of sesame milk per tube), cooled (by immersing the tubes in ice bath for $5 \mathrm{~min}$ ) and then stored refrigerated (at $4^{\circ} \mathrm{C}$ ). For sensory analysis $2 \%$ sucrose was added to sesame milk before heat treatment.

A factorial experiment was designed to investigate the interaction effect between pretreatments of sesame seed with simple physical treatments and heat treatment of the produced milk. Detailed descriptions of treatments within each factor studied are shown in Table 1. Two replicates were made for each treatment and the sample size was $50 \mathrm{~mL}$ of sesame milk.

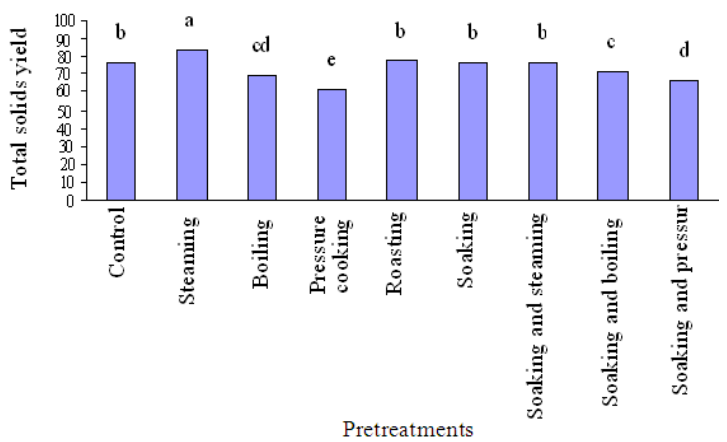

Fig. 1: Effect of pretreatments of decorticated sesame seed on total solids yield of the prepared sesame milk. Values with different letter are significantly different $(\mathrm{p}<0.05)$ according to LS-mean test 
Table 1: Factors studied during the development of sesame milk

\begin{tabular}{|c|c|}
\hline Factors & Level and description \\
\hline $\begin{array}{l}\text { Pre-treatments } \\
\text { of decorticated }\end{array}$ & $\begin{array}{l}\text { Control: Without pretreatments } \\
\text { Boiling: Sesame seed were filled in sieve and } \\
\text { immersed in boiling water for } 15 \text { min, then cooled } \\
\text { directly by immersing in cold water. } \\
\text { Steaming: Sesame seed were filled in sieve and } \\
\text { put over steam bath for } 15 \text { min, then cooled } \\
\text { directly by immersing in cold water } \\
\text { Pressure cooking: Sesame seed were filled in } \\
\text { pressure cooker, which previously filled with } 1.5 \mathrm{~L} \\
\text { boiling water, then closed and pressure cooked for } \\
15 \text { min. Timing was started after the steam began } \\
\text { to escape from the safety valve. After finishing, } \\
\text { sesame seed was cooled directly by immersing in } \\
\text { cold water. } \\
\text { Roasting: Sesame seed were roasted for } 2 \text { h in } \\
\text { commercial roaster composed from steam heated in } \\
\text { double jacketed half drum equipped with paddles } \\
\text { Soaking: Sesame seed were soaked in double its } \\
\text { weight tap water overnight } \\
\text { Soaking and boiling: Soaked sesame seed were } \\
\text { boiled as previously described. } \\
\text { Soaking and steaming: Soaked sesame seed were } \\
\text { steamed as described previously. } \\
\text { Soaking and pressure-cooking: Soaked sesame } \\
\text { seed were pressure cooked as described previously. }\end{array}$ \\
\hline $\begin{array}{l}\text { Heat treatments } \\
\text { of sesame milk } \\
\text { sesame seed }\end{array}$ & $\begin{array}{l}\text { Control without heat treatments } \\
\text { Pasteurization at } 75^{\circ} \mathrm{C} \text { for } 5 \mathrm{~min} \\
\text { Sterilization at } 121^{\circ} \mathrm{C} \text { for } 20 \mathrm{~min}\end{array}$ \\
\hline
\end{tabular}

For sensory evolution, selected samples were reproduced with a sample size of $300 \mathrm{~g}$ for each treatment. The produced milk was evaluated by measuring total solids yield, dispersion stability after one day $\left(\right.$ at $\left.4{ }^{\circ} \mathrm{C}\right)$ and sensory evaluation.

Verifying the results of the effect of pretreatments of sesame seed using the second source of sesame seed: The effects of pretreatments (Table 1), except roasting, were re-evaluated on decorticated sesame seed from the second source. In this experiment, the time of heat treatments in different pretreatments used were reduced to $5 \mathrm{~min}$ rather than $15 \mathrm{~min}$ used in the first experiment. This because using $15 \mathrm{~min}$ during different heat treatments resulted in inferior dispersion stability and total solids yield with all pretreatments. So, it was decided to reduce the time of heat treatments in different pretreatments used. From each treatment, samples of raw and pasteurized sesame milk were stored refrigerated $\left(\right.$ at $4^{\circ} \mathrm{C}$ ) for one and three days respectively. Two replicates were made for each treatment and the sample size was $50 \mathrm{~mL}$ of sesame milk. For sensory evolution, selected samples were reproduced with a sample size of $300 \mathrm{~g}$ for each treatment. The produced milk was evaluated by measuring: Percentage of total solids and protein, total solids and protein yield and dispersion satiability after one day $\left(\right.$ at $4^{\circ} \mathrm{C}$ ) for unheated (control) milks and each day during the refrigerated storage period (3 days at $4^{\circ} \mathrm{C}$ ) for pasteurized milks.

Analytical procedures used:

Moisture and protein: Moisture and protein $(\mathrm{N} \times 6.25)$ were determined by ${ }^{[1]}$.

Total solids yield and protein yield: Total solids yield of sesame milk was calculated by the following formula:

$$
\% \text { Total solids yield }=\frac{\text { Percentage of total solids in sesame milk }}{\text { Initial total solids concentration }} \times 100
$$

Protein yield of sesame milk was calculated by the following formula:

$$
\% \text { Protein yield }=\frac{\text { Percentageof protein in sesame milk }}{\text { Initial pr otein concentration }} \times 100
$$

Dispersion stability: Dispersion stability of sesame milk was determined after refrigerated storage at $4^{\circ} \mathrm{C}$ for one day for unheated milks and each day throughout the storage period for pasteurized and sterilized milks. Dispersion stability was measured by observing if there is a line separating the lower layer (condensed dispersed phase) from the above layer (clear serum phase), then the height of the dispersed phase was measured and calculated as a ratio to total height. If no line can be observed, the separation index would be $1.00^{[15]}$.

Expert panel sensory evaluation: Four panelists were selected for their experience in dairy products from the Department of Nutrition and Food Technology in the University of Jordan. All treatments (sesame products) were served at $8-10^{\circ} \mathrm{C}$. During the evaluation, each member independently, informally evaluated the treatments and expressed his opinion by a free description of what he/she likes or dislikes from the perceived sensory attributes. After that, the results were discussed with each member and, based on these discussions, group of treatments were selected for further sensory evaluation using 5-points hedonic scale or to be further improved by processing before evaluating them again.

Statistical analysis: The results were analyzed statistically by Analysis Of Variance (ANOVA) with significance at $\mathrm{p}<0.05$. The statistical analysis was 
done using SAS system. Selected regression analyses were made between percentages of protein in the produced milks against the corresponding values of control and pasteurized milk dispersion stability after one day of refrigerated storage (at $4^{\circ} \mathrm{C}$ ).

\section{RESULTS}

Effect of pretreatments of decorticated sesame seed and heat treatment of sesame milk on the quality of the produced milk:

Total solids yield:

Effect of pretreatments: The highest total solids yield value $(83.48 \%$ ) was found in steamed sesame seed with significant differences from the control $(76.77 \%)$ and the remaining pretreatments (Fig. 1). Steaming improved the total solids yield by about $8.74 \%$ in comparison with the control. Roasting, soaking as well as soaking combined with steaming did not significantly affect the total solids yield in comparison with the control. In contrast, soaking combined with boiling, boiling, soaking combined with pressurecooking and pressure-cooking reduced the total solids yield, in comparison with the control, with a reduction value of $7.29,10.58,13.66$ and $19.92 \%$ respectively.

\section{Dispersion stability:}

Effect of interaction between the pretreatments of sesame seed and heat treatments of sesame milk: As shown in Fig. 2, pasteurization of sesame milk improved the dispersion stability in comparison with control milk (not heat treated). This result is valid for all combinations between pretreatments and pasteurization, with the exception of one treatment (combination between roasting and pasteurization) in which the dispersion stability was reduced. The pasteurization improvement values ranged between $2 \%$ (which is not significant) for steaming combined with pasteurization and $131 \%$ for boiling combined with pasteurization. The highest dispersion stability values of pasteurized milks were found with the following pretreatments: soaking combined with steaming (0.91); soaking combined with pressure-cooking (0.90) and steaming (0.87). Taking in consideration the total solids yield of these treatments (76.41, 66.28 and 83.48 respectively) (Fig. 1), it was concluded that the treatment of choice was steaming, because they have the highest total solids yield and have a relatively good dispersion stability.

Regarding sterilization of sesame milk, Fig. 2 shows that sterilization of sesame milks resulted in impairing of the dispersion stability in six pretreatments out of nine. It is worthy to note that a denatured network like structure was observed in sesame milk upon sterilization.

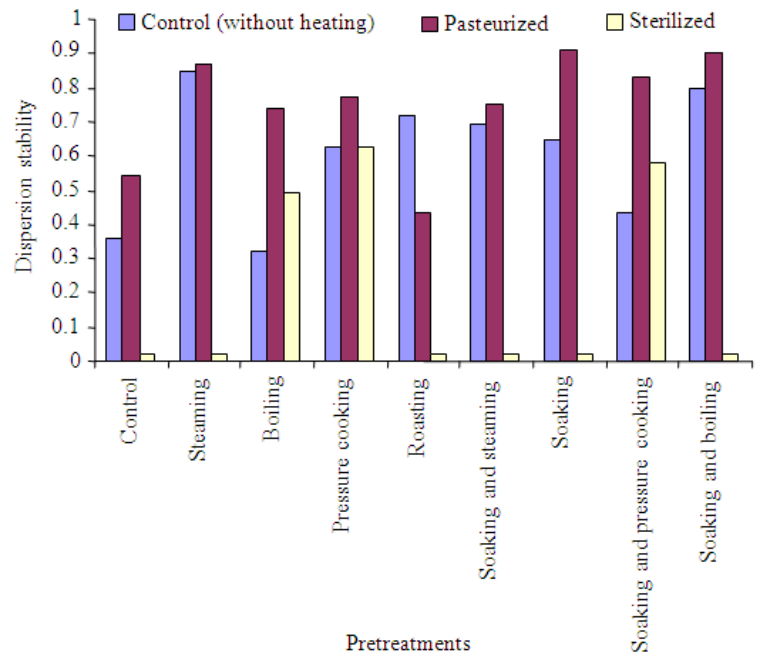

Fig. 2: Effect of interaction between pretreatments of sesame seed and heat treatments of sesame milk on the dispersion stability after one day of refrigerated storage $\left(\right.$ at $\left.4^{\circ} \mathrm{C}\right)$

The remaining three pretreatments: Boiling (with or without previous soaking step) and pressure-cooking produced milks that can withstand the sterilization treatment. However, the produced sterilized milks had inferior dispersion stability when compared with pasteurized milks combined with the same pretreatments. On the other side, when comparing the dispersion stability values of sterilized milks with those of control (not heat treated) milks combined with the same pretreatments we can see that sterilization improved the dispersion stability with milk produced from sesame seed pretreated with boiling (with or without previous soaking step) (Fig. 2).

Sensory evaluation: The expert panel sensory evaluation of selected treatments (based on the results of yield and dispersion stability) indicated that roasting, steaming (with or without previous soaking step) and pressure-cooking (with or without previous soaking step) improved the flavor acceptability (bitter and off flavors were reduced) in comparison with the other treatments. From these pretreatments, only roasted seed produced milk with a desirable flavor, while the other treatments produced milks with bland, slightly acceptable flavor. Milks with salt concentration above $0.5 \%$ were unaccepted due to their salty flavor.

Verifying the results of the effect of pretreatments of sesame seed using a second source of sesame seed: The results in Table 2 show that the control sesame seed from the second source (without pretreatments)-in 
Am. J. Applied Sci., 6 (5): 888-896, 2009

Table 2: Effect of pretreatments of sesame seed (from the second source) on total solids and protein yield and dispersion stability of the prepared sesame milk

\begin{tabular}{|c|c|c|c|c|c|c|c|c|}
\hline \multirow[b]{3}{*}{ Pretreatments } & \multirow{3}{*}{$\begin{array}{l}\text { Total } \\
\text { solids }(\%)\end{array}$} & \multirow[b]{3}{*}{ Protein $(\%)$} & \multirow{3}{*}{$\begin{array}{l}\text { Total } \\
\text { solids yield (\%) }\end{array}$} & \multirow{3}{*}{$\begin{array}{l}\text { Protein } \\
\text { yield }(\%)\end{array}$} & \multicolumn{4}{|c|}{ Dispersion stability } \\
\hline & & & & & \multirow{2}{*}{\begin{tabular}{l} 
Raw \\
\hdashline 1st day
\end{tabular}} & \multirow[b]{2}{*}{ 1st day } & \multicolumn{2}{|c|}{ Pasteurized } \\
\hline & & & & & & & 2nd day & 3rd day \\
\hline Control & $9.90 \mathrm{a}$ & $2.52 \mathrm{a}$ & $86.24 a$ & $87.63 a$ & $0.94 \mathrm{a}$ & $0.94 \mathrm{a}$ & $0.88 \mathrm{a}$ & $0.82 \mathrm{a}$ \\
\hline Steaming $5 \mathrm{~min}$ & $8.98 \mathrm{~b}$ & $2.32 \mathrm{~b}$ & $78.23 \mathrm{~b}$ & $80.39 \mathrm{~b}$ & $0.87 \mathrm{~b}$ & $0.75 \mathrm{c}$ & $0.63 \mathrm{c}$ & $0.51 \mathrm{c}$ \\
\hline Boiling 5 min & $8.74 \mathrm{c}$ & $2.11 \mathrm{c}$ & $76.18 \mathrm{c}$ & $73.27 \mathrm{c}$ & $0.56 \mathrm{c}$ & $0.48 \mathrm{e}$ & $0.41 \mathrm{~d}$ & $0.33 \mathrm{~d}$ \\
\hline Pressure cooking $5 \mathrm{~min}$ & $8.54 \mathrm{~d}$ & $1.99 \mathrm{~d}$ & $74.39 \mathrm{~d}$ & $69.27 \mathrm{~d}$ & $0.53 \mathrm{c}$ & $0.48 \mathrm{e}$ & $0.43 \mathrm{~d}$ & $0.32 \mathrm{~d}$ \\
\hline Soaking overnight & $8.81 b c$ & $2.29 \mathrm{~b}$ & $76.7 \mathrm{bc}$ & $79.89 \mathrm{~b}$ & $0.86 \mathrm{~b}$ & $0.88 \mathrm{~b}$ & $0.72 b$ & $0.66 \mathrm{~b}$ \\
\hline Soaking and steaming $5 \mathrm{~min}$ & $7.98 \mathrm{e}$ & $2.06 \mathrm{dc}$ & $69.47 \mathrm{e}$ & $71.36 \mathrm{~cd}$ & $0.38 \mathrm{~d}$ & $0.52 \mathrm{~d}$ & $0.40 \mathrm{~d}$ & $0.36 \mathrm{~d}$ \\
\hline Soaking and boiling $5 \mathrm{~min}$ & $7.82 \mathrm{e}$ & $1.82 \mathrm{e}$ & $68.08 \mathrm{e}$ & $63.20 \mathrm{e}$ & $0.29 \mathrm{e}$ & $0.42 \mathrm{f}$ & $0.34 \mathrm{~d}$ & $0.23 \mathrm{e}$ \\
\hline $\begin{array}{l}\text { Soaking and pressure } \\
\text { cooking } 5 \text { min }\end{array}$ & $7.5 f$ & $1.96 \mathrm{e}$ & $65.29 \mathrm{f}$ & $68.06 \mathrm{~d}$ & $0.32 \mathrm{e}$ & $0.53 \mathrm{~d}$ & $0.41 \mathrm{~d}$ & $0.37 \mathrm{~d}$ \\
\hline
\end{tabular}

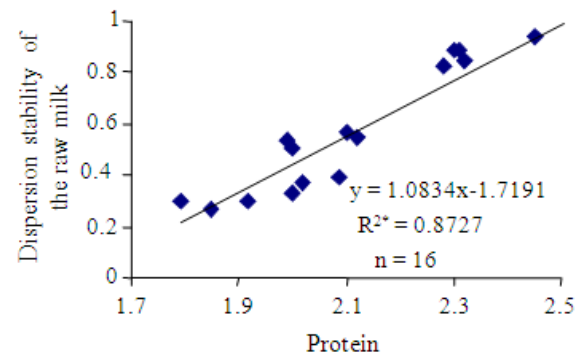

(A)

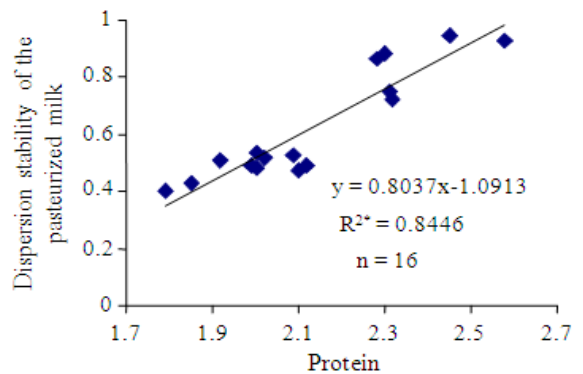

(B)

Fig. 3: Regression line between $\%$ protein in sesame milks (prepared from sesame from the second source) from different pretreated sesame seed and (A): Unheated milk dispersion stability, (B): Pasteurized milk dispersion stability after one day of refrigerated storage (at $4^{\circ} \mathrm{C}$ )

contrast with the result of sesame seed from the first source-had the highest total solids and protein yield (86.24 and $87.63 \%$ respectively) and good dispersion stability values at the first, second and third day of storage $(0.94,0.88$ and 0.82 respectively). These values were superior to the best treatment (steaming) in sesame seed from the first source (Fig. 1 and 2). For this reason, sesame from the second source was selected to continue with it the sesame milk development process.
The results of expert panel sensory evaluation showed that the control treatment for sesame milk from the second source was superior to the steaming treatment for sesame milk from the first source.

Figure 3 shows the regression lines between the percentages of protein in different milks (from different pretreated sesame) and the corresponding values of raw or pasteurized milks dispersion stability. The observed results were in contrast with that of sesame seed from the first source were no significant regression line was found.

\section{DISCUSSION}

Effect of using physical treatments to improve the yield, dispersion stability and sensory acceptance of sesame milk:

Colloidal system in sesame milk: Decorticated sesame is composed mainly of fat, protein, carbohydrates and fibers. To prepare sesame milk with the abovementioned properties, fat, protein and carbohydrates should be dispersed effectively, while insoluble fibers should be eliminated to obtain milk with desired mouth feel properties and to avoid the perception of chalkiness. The first step of sesame milk production was wet milling of sesame seed using a blender, further grinding and homogenization were performed using lab-homogenizer. Fiber separation was performed by squeezing milk base through cheesecloth.

Two types of colloidal systems exist in the produced dispersion. The first is the oil in water emulsion and the second is the solids (protein, carbohydrates) in liquid. The primary experiment performed (producing milk from sesame seed from the first source without any pretreatments) resulted in milk with inferior dispersion stability and flavor. However, a relatively good total solids yield $(76.77 \%$, Fig. 1) was obtained when compared with reported total solid yields of other vegetable milks. The inferior dispersion 
stability was obvious through rapid flocculation and sedimentation of milk solids with the ultimate formation of two distinctive layers: an upper clear serum layer and a lower condensed colloidal layer. Unexpectedly, no separation of fat or a cream layer was observed, even when the sample was pasteurized (at $75^{\circ} \mathrm{C}-5 \mathrm{~min}$ ) and stored refrigerated $\left(\right.$ at $\left.4{ }^{\circ} \mathrm{C}\right)$ for three days. From this behavior, it can be concluded that there are effective stabilizing factors in the produced milk that help in maintaining the fat in an emulsified form without separation from the dispersed particles. It is worth noting that short shaking was sufficient to return the settled layer back in a homogenous dispersion. So, it was concluded that the observed phase separation is not a colloidal breakdown; rather it is settlement due to agglomeration of colloidal particles. This relatively high stability of the formed dispersion indicates that the finely dispersed protein and carbohydrate fractions are able to form a colloidal system in combination with the oil fraction that affect not only the dispersion behavior, but also the yield of the produced milk.

The above observations are in conflict with the reported information, which indicated that isolated sesame protein had limited solubility in water between $\mathrm{pH}$ 6-7and this (according to the investigators) limits its use in certain food formulation (particularly in fluids and beverages $)^{[9]}$. This conflict between the reported information regarding sesame protein solubility and the relatively high total solids yield in the prepared milk from the primary experiment could be cleared when discussing the relationship between protein solubility and emulsification properties. It is well established that protein with low solubility helps in maximizing protein load at the interface and promotes formation of highly viscoelastic, rigid film at the interface. For instance, the proteins of serum albumin, gelatin and egg-white proteins show the maximum emulsifying activity and emulsion capacity at their isoelectric pH. However, this may be valid for thick viscous emulsions, while in more dilute emulsions this effect may minimize repulsion between adjacent droplets, facilitate contact and cause flocculation of emulsion droplets and sedimentation ${ }^{[9]}$. Additionally, the positive interaction between sesame protein, carbohydrates and sesame oil make the system quite different from observation reported on isolated protein. These facts may explain the relatively high total solids yield and at the same time low dispersion stability in the milk from the primary experiment. The presence of fat and homogenization step may facilitate the extraction of proteins by decreasing their hydrophobic attraction forces by adsorbing it at the interface of fat droplets and exposing polar groups to water. A similar observation was reported for soymilk by Priepke et al..$^{[15]}$, who concluded that the stability of soymilk is promoted by formation of a lipid-protein complex. The phase separation observed in the prepared sesame milk may be related to the low repulsion forces between the dispersed droplets and as a result, flocculation and sedimentation occurred.

The need for sesame protein modification to improve their functional properties: The results of the primary experiments revealed the need for improvement of dispersion stability, flavor and yield. To improve the dispersion stability, two factors were investigated, (1) pretreatments of decorticated sesame seed by simple physical treatments, (2) heat treatment of the produced sesame milk. All of these factors were reported to have an effect on protein conformational structure (denaturation).

Effect of heat treatments: In this study, heat treatments were tested at three stages during sesame milk production, (1) during commercial drying process after decortication process, (2) during the pretreatments of decorticated sesame seed, (3) during heat treatment of the produced sesame milk.

Yield and dispersion stability: Heat treatment of decorticated sesame seed from the first sesame source improved the total solids yield (Fig. 1) and dispersion stability (Fig. 2) and the best pretreatment in this regard was steaming. Pasteurization of milks prepared from the pretreated seeds further improved the dispersion stability, while sterilization of sesame milk impaired the dispersion stability (Fig. 2). It can be concluded that the heat treatments of sesame seed and heat treatment of the milk both affect the dispersion stability and quality of the produced milk in a complementary manner. Using sesame seed exposed to a high temperature during drying after the decortication process (sesame seed from the second source) without further pretreatments produced milks with a superior quality to that prepared from steamed sesame seed from the first source (dried in temperatures not exceeded $55^{\circ} \mathrm{C}$ ). From these results, it was concluded that the heat treatments during drying of the sesame seed from the second source seems to be equivalent to that of steaming of the seed from the first source. Since a better milk quality was produced from sesame seed from the second source, subsequent sesame milk developing steps were continued with it. The effect of different heat treatments at different processing steps could be related to their influence on sesame protein solubility, which is supposed to alter their emulsifying properties. As reported by Kinsella and the protein of sesame seed is composed of a three disulfide-linked 
dimeric (acidic and basic) subunits associated noncovalently to form a hexameric structure. This joins with another identical ring (via hydrogen bonding and hydrophobic and electrostatic interactions) to form the oligomeric molecule. Extra-unpaired subunits are associated with opposed rings to form the native $\alpha$ globulin, which is the major protein in sesame seed ( $70 \%$ of the total proteins) and the only one investigated. The increased solubility due heat treatment may be caused by the denaturation of sesame proteins, which may lead to exposure of hydrophilic sites or may cause dissociation of sesame protein subunits that may exhibit more desirable functional properties. Denaturation denotes a process (or sequence of processes) in which the spatial (configuration, conformation and state of folding) arrangement of polypeptide chains within the molecules is changed from that typical of the native protein to a more disordered arrangement. Generally it involves disruption of the noncovalent forces responsible for the organization of the native structure, although in some cases it may include rupturing of disulfide bonds ${ }^{[9]}$. The total solids yield differences between pretreatments could be related to the difference in heat treatment that the sesame protein was subjected to it, which in turn affects the degrees of denaturation in a manner that increase or decrease the association of protein.

The dispersion stability of milk from sesame seed from the second source could not be further improved by pretreatments (in contrary to the behavior of sesame seed from the first source with different pretreatments), instead any pretreatments resulted in a reduction of milk dispersion stability and protein yield. The reduction in dispersion stability and yield could be related to the re-polymerization and aggregation (disulfide bonds may be involved) of the previously unfolded proteins (by the action of heating during drying) and subsequent formation of large aggregates that are not extractable with water during milk preparation. Another difference between the two types of sesame seed was apparent when plotting total solids yield and protein yield (in case of sesame seed from the second source) against the corresponding dispersion stability values of the pasteurized milk after one day of refrigerated storage (Fig. 3). In case of sesame seed from the first source, no significant regression line could be observed (data not shown). In other words, dispersion stability was independent of yield; rather it is dependent on the functionality of the extracted protein. This was apparent when comparing (for example) the control treatment (not pretreated) with roasting, soaking and soaking combined with steaming in terms of total solids yield and dispersion stability. All of these treatments did not differ in total solids yields (Fig. 1), but they differed in dispersion stability values of the produced milks (Fig. 2). Another example is the effect of soaking combined with pressure cooking treatment, which resulted in a low total solids yield $(66.28 \%$, Fig. 1) but at the same time they had pasteurized milk with high dispersion stability $(0.90$, Fig. 2$)$. This seems to be related to the extraction of certain fractions of protein with improved solubility and emulsifying properties. For sesame seed from the second source a significant regression line was observed, which means that the dispersion stability of sesame milk is dependent on the yield.

Sensory quality: The results of the sensory evaluation revealed that there is a group of pre-treatments (on sesame seed from the first source) having acceptable flavor such as: roasting, steaming (with or without previous soaking step) and pressure-cooking (with or without previous soaking step). Only milk from roasted seed gave a desired flavor while other treatments of this series gave somewhat bland slightly accepted flavors. The production of a desirable flavor in milk prepared from roasted sesame seed was expected, since roasting is known to improve the flavor of all seeds and nuts. Ashri $^{[2]}$ reported that the production of flavoring compounds are assumed to be produced by Maillard reactions of sugars and amino acids in sesame seed. However, due to the low dispersion stability of pasteurized sesame milk from roasted seed (0.43) (Fig. 2), roasting as pretreatment was excluded. Though, it is worth to investigate the effect of dry heat roasting at different temperatures and times on the dispersion stability of sesame seed solids. Sesame seed from the second source (without any pretreatments), produced sesame milk with superior quality to that produced from sesame seed from the first source with the exception of milk prepared from roasted sesame. Al-Malah and Mukbel (unpublished data) indicated that the perception of bitter taste could be related to the hydrophobicity of sesame proteins and decreasing the hydrophobicity (reducing the size of protein) can reduce the intensity of bitter taste. The authors indicated that decreasing the size of sesame protein molecules and subsequent reduction in bitterness could occur by the action of sesame embedded cellular enzymes during storage. This effect can be accelerated by soaking sesame seed in $0.4 \% \mathrm{NaHCO} 3$ solution for $30 \mathrm{~min}$ at $40^{\circ} \mathrm{C}$. For this reason, the improvement of sesame protein solubility by different heat treatments used in this study could be partially responsible for the improvement of the prepared sesame milk flavor (particularly for milk prepared from sesame seed from the first source). 
Am. J. Applied Sci., 6 (5): 888-896, 2009

\section{CONCLUSION}

The study revealed for the first time the possibility of producing sesame milk. The new products offer a family of dairy analogues, which can be declared as health foods that can be used as dairy substitutes or extenders. Sesame seed proteins prove to have good functional properties to be utilized in the production of sesame milk if suitable processing factors are considered. In this study it was found that heat treatments during all steps of sesame milk production played the major role in determining the quality of the produced milk regarding yield, dispersion stability and sensory acceptability. The produced milk tolerated the pasteurization temperature, while they did not tolerate the sterilization temperature that indicates the sensitivity of sesame protein to heat treatment.

\section{REFERENCES}

1. Kim, M.K. and R.T. Lovell, 1995. Official Methods of Analysis, Association of Official Analytical Chemists, Virginia. 16th Edn., Cunniff, Arlington, VA., USA., pp: 1141. https://commerce.metapress.com/content/4x737211 quw30428/resource-

secured $/$ target=fulltext.pdf $\&$ sid $=q 03$ rokaduh 1 inz 5 5132to355\&sh $=$ www.springerlink.com

2. Nelson, A.I., W.B. Wijeratne, S.W. Yeh, T.M. Wei and L.S. Wei, 1997. and Recommended Practices of the AOCS5 ,th ednAOCS. (1997). Protein Dispersibility Index (PDI). AOCS official method $\mathrm{Ba} \quad 10-65,1-3$. europe.org/pdf/ASA_Manual_CHAP_11

http://www.springerlink.com/content/f6n7g5q4097953j6/

3. Beuchat, L.R. and B.J. Nail, 1978. Fermentation of peanut milk with lactobacillus bulgaricus and L. acidophilus. J. Food Sci., 43: 1109-1112. http://www3.interscience.wiley.com/journal/1 19613976/

4. Boloorforooshan, M. and P. Markakis, 1979. Protein supplementation of navy beans with sesame. J. Food Sci., 44: 390-391. DOI: 10.1111/j.1365-2621.1979.tb03795

5. Brough, S.H., S.N. Azam-Ali and A.J. Taylor, 1993. The potential of bambara groundnut (vigna subterranean) in vegetable milk production and basic protein functionality systems. Food Chem., 47: 277-283.

6. Bucker, E.R., J.H. Mitchell and M.G. Johnson, 1979. Lactic fermentation of peanut milk. J. Food Sci., : 1934-1938.

http://www3.interscience.wiley.com/journal/12001 6583/abstract

7. Evans, R.J. and S.L. Bandemer, 1967. Nutritive values of some oilseed proteins. Cereal Chem., 44: 417.

http://aaccnet.org/cerealchemistry/abstracts/1967/c c1967a47.asp
8. Hirotsuka, M., H. Taniguchi, H. Narita and M. Kito, 1984. Calcium fortification of soy milk with calcium-lecithin liposome system. J. Food Sci., 49: 1111-1112. http://www.fao.org/docrep/W2840E/w2840e0b.ht $\mathrm{m}$

9. Kapadia, G.J., M.A. Azuine, H. Tokuda, M. Takasaki, T. Mukainaka, T. Konoshima and H. Nishino, 2002. Chemopreventive effect of resveratrol, sesamol, sesame oil and sunflower oil in the epstein-barr virus early antigen activation assay and the mouse skin two-stage carcinogenesis. Pharmacol. Res., 45: 499-505.

10. Kinsella, J.E., S. Domodarn and B. German, 1985. Physiological and Functional Properties of Oilseed Proteins with Emphasis on Soy Proteins. In: New Protein Foods, Atschul A.A. and H.L. Wilcke (Eds.). Academic Press, Orlando, pp: 107-179. http://www.sciencedirect.com/science?_ob=Article URL\&_udi=B6T6R-3RH10VF-

G\&_user=4731503\&_rdoc $=1 \&$ fmt $=$ \&_orig $=$ searc h\&_sort=d\&view $=$ c\&_version $=1 \&$ \&urlVersion $=0$ \&_userid $=4731503 \& \mathrm{md} 5=3 \mathrm{~b} 22 \mathrm{~d} 1110208 \mathrm{f} 02510 \mathrm{fa}$ $0 \mathrm{e} 7 \mathrm{~b} 58 \mathrm{~b} 5 \mathrm{a} 2 \mathrm{c} 9$

11. Mahajan, A., S. Bhardwaj and S. Dua, 1999. Traditional processing treatments as a processing approach to enhance the functional properties of rapeseed (brassica campestris var. toria) and sesame seed (sesamum indicum) meals. J. Agric. Food Chem., 47: 3093-3098.

http://search.msn.com/results.aspx?q=Mahajan $\% 2$ $\mathrm{C}+\mathrm{A} . \% 2 \mathrm{C}+\mathrm{Bhardwaj} \% 2 \mathrm{C}+\mathrm{S}$.+and+Dua $\% 2 \mathrm{C}+\mathrm{S} .+$ $\% 281999 \% 29 .+\mathrm{J} .+$ Agric.+Food + Chem. $\% 2 \mathrm{C}+47 \%$ $2 \mathrm{C}+3093-3098 . \&$ form $=\mathrm{QBNO}$

12. Morris, J.B., 2002. Food, Industrial Nutraceutical and Pharmaceutical Uses of Sesame Genetic Resources. In: Trends in New Crops and New Uses, Janick, J. and A. Whipkey, (Eds.). ASHS Press, Alexandria, VA., pp: 153-156. http://www.rci.rutgers.edu/ raskin/sci.html

13. Nakano, D., C. Itoh, M. Takaoka, Y. Kiso, T. Tanaka and Y. Matsumura, 2002. Antihypertensive effect of sesamin. IV. Inhibition of vascular superoxide production by sesamin. Biol. Pharm. Bull., 25: 1247-1249. DOI: $10.1248 / \mathrm{bpb} .25 .1247$

14. Noguchi, T., K. Ikeda, Y. Sasaki, J. Yamamoto, J. Seki, K. Yamagata, Y. Nara, H. Hara, H. Kakuta and Y. Yukio, 2001. Effects of vitamin $\mathrm{E}$ and sesamin on hypertension and cerebral thrombogenesis in stroke-prone spontaneously hypertensive rats. Hypertens. Res., 24: 735-742. http://search.msn.com/results.aspx?q=+\%282001\%29.+E ffects+of+vitamin+E+and+sesamin+on+hypertenson+an $\mathrm{d}+$ cerebral+thrombogenesis+in+stroke-

prone+spontaneously+hypertensive+rats. + Hyperte ns.+Res. $\% 2 \mathrm{C}+24+\% 286 \% 29 \% 2 \mathrm{C}+735-$

742.\&form $=\mathrm{QBNO}$ 
15. Oshodi, A.A., H.N. Ogungbenle and M.O. Oladimeji, 1999. Chemical composition, nutritionally valuable minerals and functional properties of benniseed (Sesamum radiatum), pearl millet (Pennisetum typhoides) and quinoa (Chenopodium quinoa) flours. Int. J. Food Sci. Nutr., 50: 325-331.

http://www.fonteine.com/quinoa.html

16. Priepke, P.E., L.S. Wei, A.I. Nelson and M.P. Steinberg, 1980. Suspension stability of illinois soybean beverage. J. Food Sci., 45: 242-245. http://www.kmutt.ac.th/CRDC_symposium/data/11 9-122.pdf

17. Rao, D.R., S.R. Pulusani and C.B. Chawan, 1988. Technical note: preparation of a yoghurt-like product from cowpeas and mung beans. Int. J. Food Sci. Technol., 23: 195-198. http://www.tfljournal.org/article.php/20051201124 931586
18. Sirato-Yasumoto, S., M. Katsuta, Y. Okuyama, Y. Takahashi and T. Ide, 2001. Effect of sesame seeds rich in sesamin and sesamolin on fatty acid oxidation in rat liver. J. Agric. Food Chem., 49: 2647-2651.

http://www.bioline.org.br/request?jb07431

19. Toma, R.B. and M.M. Tabekhia, 1979. Phytate and oxalate contents in sesame seed. Nutr. Rep. Int., 20: $25-31$.

http://www.scribd.com/doc/5340623/Handbook-ofHerbs-and-Spices-Volume-2 